\title{
17 Narrative processes of innovation and stability within the dialogical self
}

\author{
Miguel M. Gonçalves and António P. Ribeiro
}

In dialogical self theory (DST), the way dialogical relations allow innovation and transformation of the previous dialogical patterns is of central importance (Hermans 2004). In this chapter we explore a dialogical process through which innovation is aborted in psychotherapy - a cyclical movement between two opposing voices, one dominant that organizes the client's problematic self-narrative, and one innovative, non-dominant voice. We also discuss two different paths of escaping this cyclical movement. In the first path the innovative voice gains power over the previously dominant one, while in the second path the two opposing voices engage in dialogue, transforming them. These processes will be illustrated with two different cases from psychotherapy. Finally, we analyse the implications of our findings by DST.

\section{Self-narratives and the dialogical self}

Self-development is regulated by processes of construction and reconstruction of meanings which occur in the context of narrating oneself to others. Each narrative account has external audiences or, as with stories told silently to oneself, internal audiences (Hermans 2003).

However, constructing a self-narrative, that is, a self-told life story by which the singular events narrated come to be articulated, is not simply a matter of organizing life events as they occur. In fact, it also entails a process of selection and synthesis of life experience (McAdams 1993) since only a small part of the multitude of the person's experiences is incorporated into the self-narrative (White and Epston 1990). This process of self-narrative construction is dialogical, in the sense that a self-narrative, as Hermans and Kempen (1993) have clearly shown, is not the result of an omniscient narrator, but the result of the dynamic interplay between the positions of the self, or I-positions, which organize the self at a given moment. These several $I$-positions may then animate inner and outer dialogues, in which several 'voices' can be heard and give meaning to the current experience. 
In sum, self-narratives are the outcome of dialogical processes of negotiation, tension, disagreement, alliance and so on, between different voices of the self (Hermans and Hermans-Jansen 1995).

\section{Problematic self-narratives}

Self-narrative presents a meaningful framework of understanding life experiences, triggering repetition (Michel and Wortham 2002). This repetition becomes a problem if the self-told life story's content is 'unhelpful, unsatisfying, and dead-ended' and if 'these stories do not sufficiently encapsulate the person's lived experience' (White and Epston 1990: 14); that is, if the self-narrative is too rigid and systematically excludes experiences not congruent with it. Neimeyer et al. (2006) refer to this type of problematic self-narratives as dominant narratives, in the sense that there is a restriction in the meanings framed by the self-narrative. In such a case, they lead to applications of general rules (such as self-devaluation in depression) to the daily life context, becoming restrictive of clients' experiences, given that the same theme keeps repeating itself. Dominant self-narratives emerge in the client's dialogue, usually by the emphasis on a main theme, which can be a specific problem or a problematic situation, or even a set of recurrent themes.

As stated by Hermans and Hermans-Jansen, a problematic self-narrative is a 'narrative reduced to a single theme' (1995: 164). Obviously, we do not think that all forms of dominance are problematic. Most of the time, the self is stabilized around a type of dominant narrative, which is flexible enough to allow other narrative accounts subsequently to come to the foreground. By dominant narrative, Neimeyer et al. (2006) refer to a kind of dominance that precludes any flexibility to allow other narrative accounts to play a role in a person's life. This is akin to what White and Epston (1990) designate as problem-saturated narrative, in the sense that the problematic story totalizes the self, making other possible narrative accounts invisible. Thus, from now on, we use the term 'dominant narrative', implying this problematic facet, which results from the lack of flexibility and from excessive redundancy.

Dominant self-narratives are characterized by an asymmetrical relationship between the different $I$-positions involved. There is an $I$-position or a coalition of $I$-positions that tries to totalize the interchange (Cooper 2004), insisting on telling the same story over and over again. It is this redundancy that constitutes the problematic nature of the dominant self-narrative, given that other possible I-positions, some of them more viable for the current situation, are silenced or rejected. 
The result of this type of $I$-position arrangement mirrors an attempt to deny the dialogical nature of existence and communication (Linell and Marková 1993).

\section{The entry way for narrative reconstruction: innovative moments}

As Bakhtin (1984/2000) suggested, the attempt to suppress the other (external or internalized) is never totally accomplished (Gonçalves and Guilfoyle 2006; Salgado and Gonçalves 2007; Valsiner 2004). Thus, internal (and external) voices are not inert and refuse to be treated as objects, devoid of agency. They could be silenced but they are still there, and power unbalances may occur that bring these silenced voices from the background to the foreground (Hermans 2004). According to this view, dominant self-narratives can be challenged by the emergence and amplification of 'novel ways of thinking, interacting, and behaving that the client narrates in the therapeutic conversation, which are different from the rule(s) he or she usually applies to his or her life' (Santos and Gonçalves 2009: 493). We consider these exceptions to the dominant self-narrative - which we call innovative moments $(I M s)^{1}$ - as new emergent meanings that have the latent power to promote change in psychotherapy (Gonçalves et al. 2009; Gonçalves et al. 2010). Dialogically, IMs are opportunities for new I-positions to emerge and tell their own stories, different from the dominant selfnarrative, or even for non-dominant I-positions to move from the background to the foreground. If these alternative $I$-positions support each other and are amplified in the therapeutic conversation, they may result in the emergence of a network of interconnected I-positions which compete with the formerly dominant ones, attenuating their strength, and thereby promoting self-narrative transformation. In therapy, every time these dominated voices are heard, a novelty emerges in the self-system, which we call an IM. An IM is thus an exception to the rule which organizes the dominant self-narrative. As we shall see below, some exceptions are more powerful than others, some may emerge without significant change in the self-system equilibrium, and others disrupt more easily the dominant self-narrative, creating selfdevelopment.

Previous research has consistently shown that IMs can be reliably identified, using the innovative moments coding system (IMCS) (Gonçalves, Ribeiro, Matos et al. in press), and that they occur in psychotherapeutic change in different models of brief therapy (Gonçalves et al. 2010). Furthermore, research suggests that there 
are five different categories of IMs, which correspond to different narrative processes, namely:

1. Action IMs are specific behaviours which challenge the dominant selfnarrative.

2. Reflection IMs are thoughts, feelings, intentions, projects or other cognitive products which challenge the dominant self-narrative.

3. Protest IMs entail new behaviours (like action IMs) and/or thoughts (like reflection IMs) which challenge the dominant self-narrative, representing a refusal of its assumptions. This active refusal is the key feature that allows the distinguishing of protest from action and reflection.

4. Reconceptualization IMs are the most complex type of innovations. The client not only describes some form of contrast between present and past (e.g. 'Now I've changed X or Y'), but he also understands the processes which allowed this transformation.

5. Performing change (previously named as new experiences) IMs are new aims, experiences, activities or projects, anticipated or in action, as a consequence of meaningful changes developed so far.

Thus far, findings from IMs in psychotherapy research have shown that poor and good outcome cases tend to be similar in the beginning of the therapeutic process, both characterized by IMs of action, reflection and protest. In the middle of the treatment, two significant differences start to differentiate good from poor outcome cases. First, action, reflection and protest IMs, which are dominant in the initial phase of therapy, usually increase their presence in good outcome cases and remain stable or even decrease in poor outcome cases. Second, and more important, as we shall see below, reconceptualization and performing change emerge and increase until the end of the treatment in good outcome cases, and are virtually absent in poor outcome ones (Matos et al. 2009).

From these studies our research team developed a heuristic model of change (Gonçalves et al. 2010) which posits reconceptualization as a central feature of successful psychotherapy. According to this model, action, reflection and protest IMs emerge in the beginning of the therapeutic process, starting the development of novelty emergence. However, the emergence of reconceptualization in the middle and late phases of the therapeutic process is central in developing and sustaining meaningful change. Two main features of reconceptualization are central in this process: it establishes a contrast between the formerly dominant position and the innovative position, and it allows access to how this transformation between the former and the new position occurred. Thus, reconceptualization posits the person as an author of the change, 
given the access to the process through which change is occurring, from a meta-position (Dimaggio et al. 2003; Hermans 2003; see also Dimaggio's chapter in this volume). By doing so, reconceptualization also allows us to give coherence to the other, more episodic IMs; namely action, reflection of protest and shaping a new narrative of the self. Performing change IMs, which appear usually after reconceptualization, represent the expansion of the change process into the future.

Our suggestions about the importance of the meta-position involved in reconceptualization IMs are congruent with other dialogical scholars' proposals. For example, Hermans (2003) has suggested that an observer position which manages the repertoire of positions is a necessary condition for successful psychotherapeutic change. This same process has been repeatedly researched by Dimaggio and colleagues (Dimaggio and Lysaker 2010), regarding metacognitive processes in therapy. Metacognition is a set of abilities, involving the capability to understand one's own (and others') emotional and cognitive processes and change them, which are stimulated in the psychotherapeutic process. This research makes it clear that these abilities are lacking or underdeveloped in the most disturbed patients (e.g. personality and psychotic disorders).

\section{IMs, discontinuity and continuity restoration: the centrality of uncertainty}

What processes block the path of successful psychotherapy in poor outcome cases? Why do the poor outcome cases fail to follow the pattern of increasing duration of IMs and the development from action, reflection and protest IMs into reconceptualization and performing change, in the middle and late phases of therapy?

Answering these questions involves taking into consideration IMs' potential to generate discontinuity and uncertainty, given that every innovation disrupts the usual, taken-for-granted, meaning-making processes. In fact, as Abbey and Valsiner (2005) suggest, 'all development is inherently based on overcoming uncertainty' (paragraph 14). When a system is disrupted by a significant modification, discontinuity is generated and the system must be rearranged or modified until relative stability is found again (Zittoun 2007). Accordingly, Hermans and Dimaggio have pointed out that although 'uncertainty challenges our potential for innovation and creativity to the utmost', it also 'entails the risks of a defensive and monological closure of the self and the unjustified dominance of some voices over others' (2007: 10).

Thus, sometimes, the emergence of IMs leads the self to strive to restore its sense of continuity, protecting itself from uncertainty, by 
aborting novelty exploration and returning to the dominant previous self-narrative. In the next section we further discuss this defensive movement facing innovation, which, if persistent during psychotherapeutic treatment, could lead to an unsuccessful outcome.

\section{Mutual in-feeding and problematic self-stability}

Each IM can be construed as a microgenetic bifurcation point (Valsiner and Sato 2006), in which the client has to resolve uncertainty; that is, the tension between two opposing voices - one expressed in the dominant self-narrative and the other expressed in the emerging IM. The client has to choose the direction of meaning construction, which, according to Valsiner (2008), can entail either semiotic attenuation or semiotic amplification.

Semiotic attenuation refers to the minimization, depreciation or trivialization of a particular innovative way of acting, feeling or thinking; that is, the maintenance of the old patterns. Inversely, semiotic amplification refers to the expansion of a given innovative way of acting, feeling or thinking, creating an opportunity to change and development to occur. This represents, after the emergence of the innovative voice, its permanence in the foreground, rejecting the control of the dominant voice. Looking at the therapeutic change as a developmental process, we argue that this microgenetic process, that is, choosing between IMs attenuation and amplification at each bifurcation point, may influence ontogeny by promoting change or protecting stability. This choice depends on the dialogical relations between the problematic voice(s) and innovative ones at a given moment and on the dialogical encounter with an other - the therapist.

Frequently, in poor outcome cases, particularly in the initial and middle phases of good outcome cases, clients tend to resolve the discontinuity created by the emergence of an IM, by attenuating its meaning, making a quick return to the dominant self-narrative. This may result in the disappearance of a particular innovative way of feeling, thinking or acting (Figure 17.1), reinforcing the power of the dominant self-narrative and, thus, promoting self-stability. By doing so, clients temporarily avoid discontinuity, but do not overcome it, as the non-dominant voice continues to be active and, thus, IMs emerge recurrently. Hence, each new IM is a new opportunity for a new attenuation through the return to the dominant self-narrative. In some cases this struggle between the dominant self-narrative and the IMs continues during the entire psychotherapeutic process. We have here two opposing wishes (expressed by two opposing voices): to keep the self stable, avoiding discontinuity and 


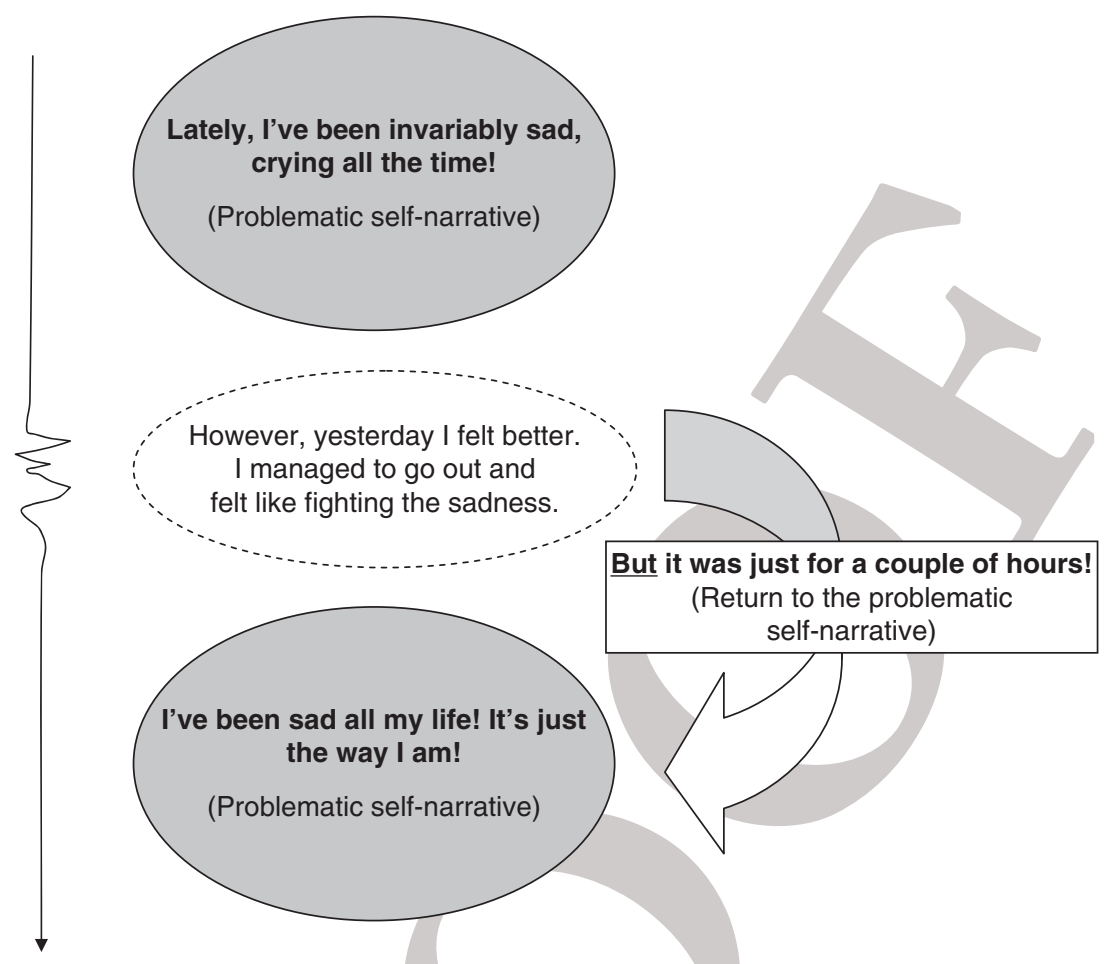

Figure 17.1 Restoring continuity through semiotic attenuation.

Source: Ribeiro and Gonçalves (2010). Adapted with permission.

the uncertainty generated by it, and to change the self, avoiding the suffering which the dominant self-narrative implies. When novelty emerges, the person 'resolves' the problem of discontinuity by returning to the dominant narrative. When the client feels too oppressed by the dominant self-narrative, he or she 'resolves' this problem by trying to produce novelty, but of course this poses the problem of discontinuity once again. Thus, the self is trapped in this cyclical relation, making ambivalence impossible to overcome within this form itself. This mirrors a form of stability within the self, in which two opposite I-positions keep feeding each other, dominating the self alternatively, a process which Valsiner (2002) has called 'mutual in-feeding' (see also Gonçalves et al. 2009; Gonçalves, Ribeiro, Conde et al. in press).

Mutual in-feeding allows for the maintenance of the person's status $q u o$, protecting one's self-identity and sense of integrity or coherence 
(Ecker and Hulley 1996; Kelly 1955; Mahoney 1991). People who seek psychotherapeutic help look for personal change but often discover that change creates unpredictability and uncontrollability (Arkovitz and Engle 2007).

In what follows, it is not our intention fully to address why clients 'resist' change, but rather to draw attention to the dialogical processes involved in the maintenance of self-narratives in psychotherapy and the way we have been empirically observing them.

\section{The empirical study of mutual in-feeding: the return-to-the-problem markers}

We have proposed a measure of the mutual in-feeding process which grew from our observations of therapy passages in which an IM emerged and is immediately followed by a return to the problematic experience. We called such events a return-to-the-problem marker (RPM). For example:

I don't want to be depressed anymore (reflection IM), but I just can't (RPM).

In this example, the client described an IM - I don't want to be depressed anymore - and then returned to the problematic voice by saying, but I can't. This clause introduced by the word but represents opposition or negation towards what is being said and hence constitutes the RPM.

The results obtained in a sample of narrative therapy with women victims of domestic violence showed that IMs were much more likely to be followed by a return to the dominant self-narrative in poor outcome cases than in good outcome cases (Gonçalves, Ribeiro, Conde et al. in press). Even though the cases had similar levels of symptom severity at intake, poor outcome cases showed dramatically higher percentages of IMs containing RPMs. This observation is consistent with the theoretical suggestion that mutual in-feeding between the dominant selfnarrative and IMs can interfere with therapeutic progress (Gonçalves et al. 2009). Furthermore, we found a lower incidence of RPMs in reconceptualization and performing change IMs than in reflection and protest IMs, and this is congruent with the theoretical assumptions (Gonçalves, Ribeiro, Conde et al. in press), corroborating reconceptualization and performing change as markers of sustained therapeutic change.

\section{Overcoming mutual in-feeding throughout the therapeutic process}

Although RPMs as a marker of mutual in-feeding are more characteristic of unsuccessful psychotherapy, they may also offer opportunities for 
constructive therapeutic work. In fact, when mutual in-feeding is overcome, it could facilitate the change process, given that the struggle between the opposing voices is solved. Therefore, we have initiated a line of intensive qualitative research into how RPMs can turn into therapeutic movement; that is, how the relation between non-dominant voices and the dominant voices evolves from mutual in-feeding to another form of dialogical relation. Hitherto, we have identified two possible processes: (1) Escalation of the non-dominant voice(s) and thereby inhibiting the dominant voice, and (2) negotiating and engaging in joint action. Below, these processes are illustrated in two cases.

Overcoming mutual in-feeding through escalation of the non-dominant voice(s) and thereby inhibiting the dominant voice: the case of Susan

Susan (a pseudonym) was a 38-year-old participant in a study of IMs in women victims of intimate violence followed in narrative therapy (Matos et al. 2009). In the initial phase of the therapy, Susan often oscillated between two contrasting positions: the dominant voice, which was described as justifying her husband's violent behaviours and even feeling responsible for them, leading her to keep forgiving him (e.g. 'things will change as time goes by') - a forgiving voice - and the non-dominant voice, which was described as thoughts and feelings that challenge the forgiving voice; that is, realizing that her husband was responsible for his actions and resisting internal and external pressures to forgive him (e.g. 'I've had enough!') - a resisting voice.

The following example illustrates the escalation of the resisting voice and the subsequent inhibition of the forgiving voice, resolving mutual in-feeding.

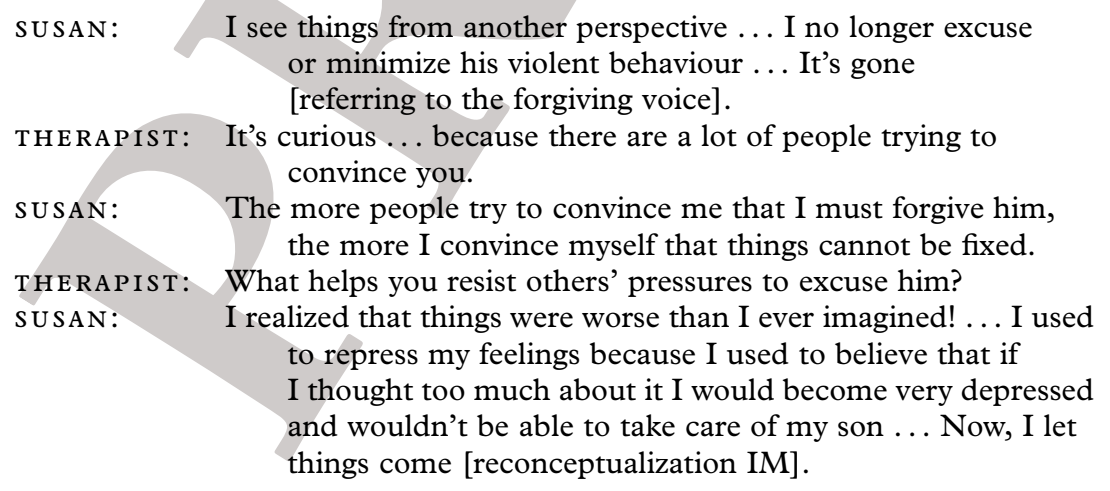
to repress my feelings because I used to believe that if I thought too much about it I would become very depressed and wouldn't be able to take care of my son ... Now, I let things come [reconceptualization IM]. 
In this example, as a result of realizing that 'things were worse than I ever imagined!', the resisting voice escalates ('I no longer excuse or minimize his violent behaviour') and strives towards regulating the forgiving voice ('I convince myself that things cannot be fixed'), inhibiting its power ('It's gone [referring to the forgiving voice]').

This dialogical process can move towards a monological outcome (see Valsiner 2000 on process versus outcome distinction) since, although the opposing voices are in dialogue, the type of interaction is very asymmetrical. Hermans (1996a, 1996b) has characterized this process as a form of dominance reversal: the position that was once dominant is now dominated. However, in this example, the process does not stop with the reversal of the I-positions; there is an escalation of the power of the resisting voice and a strong inhibition of the dominated $I$-position, in this case the forgiving voice.

One can argue that this process of escalating one voice and inhibition of the other may risk creating another dominant self-narrative, given that once again a dominant I-position took over the others. However, we suspect that sometimes meaningful clinical changes occur by this process, as in Susan's case. First, the new dominant voice is more adjusted and congruent with Susan's preferences. Second, the dominance did not occur automatically, but resulted from the client's choice. We proposed that this was mediated by a metaposition over the reversal process, without which a reversal of positions may have been a mere substitution of one problematic pattern for another. Actually, this meta-position is present in the reconceptualization IMs as it was described before.

From our narrative view, and following Sarbin (1986), we suggest that the first form of dominance, which was present in the beginning of therapy in Susan's case, has positioned her as the actor of a narrative which she did not author. In the last form of dominance, Susan was the author of her own plot. We further suggest that the meta-position involved in the dominance reversal is essential to ensure this position of authorship. One important reason is that there is not only one position which dominates and silences others, but also a third one which manages the kind of dominance involved. Instead of two forces opposing each other, we have three positions: the dominant, the nondominant and the meta-position which manages them. Thus, this new form of dominance is much more flexible than the previous one, and this flexibility is in part ensured by the meta-position (or authorship) involved.

In some cases, this asymmetrical regulation may be a transitory stage in the process of change, facilitating the client's adaptation to the 
immediate future in a given moment (e.g. a specific decision-making process: to leave or not to leave home, in the case of Susan). For instance, Susan worked towards the inhibition of the forgiving voice, which, according to her, was harmful. Congruently, these moments of monologization, in which a specific voice considered as helpful 'function[s] at a certain moment as an anchorage point around which the entire self-system organizes itself' (Rosa and Gonçalves 2008: 103), may be effective in the reduction of the ambivalence. Thus, this process of voices reversal may be a temporary stage which facilitates other subsequent, meaningful changes. While in the beginning Susan's life was constrained by the forgiving voice, and she was left without any choice about her future (besides continuing to forgive the abuse), now the dominance of the resisting voice allows new $I$-positions to come to the fore. For instance, Susan started to invest in a broader multiplicity of positions ('there are things that I recovered, things that I am doing again and that I will never again give up doing'). Thus, the potentiality for monologization of the self is precluded not only by the meta-position we referred above, but also by the multiplicity of positions which were stimulated by the inhibition of the problematic voice (the forgiving voice).

\section{Overcoming mutual in-feeding through negotiating} and engaging in joint action: the case of foan

Joan (a pseudonym) $)^{2}$ was a 42 -year-old female participant in a randomized clinical trial comparing process experiential/emotion-focused therapy with client-centred therapy (Greenberg and Watson 1998; see Honos-Webb et al. 1999 for the analysis of the assimilation process in this case).

In the beginning of therapy, Joan oscillated between two opposing voices: the dominant voice, which was described as seeking others' approval (e.g. 'I guess I'm scared I'll end up alone') - a good-girl voice and the non-dominant voice, which was described as thoughts and feelings that challenge the good-girl voice (e.g. 'I think deep down I know I'm strong enough that I could survive on my own') - a rebellious voice.

The following example illustrates the negotiation between the good-girl and the rebellious voices, resolving mutual in-feeding (a twochair $^{3}$ dialogue between the good-girl voice and the rebellious voice):

JOAN : It's always like I see myself as two split personalities [referring to her two voices] as two altogether different people and...

THERAPIST: So, who's sitting there right now? Which one is sitting there? 
JOAN: I feel like the stronger part of me [referring to the rebellious voice] now is thinking, go over and come together, and it's overpowering and overpowering the weaker person [referring to the good-girl voice]...

JOAN : I wonder if it's a way to, to be supportive and to lend strength [reflection IM]

THERAPIST: So kind of like ... it just all of a sudden happened? JOAN: Yes.

THERAPIST: So somehow it's almost like you didn't have to ask her - for what you wanted - and she didn't have to sort of tell you, it's sort of like, she, just kind of came over and you feel stronger.

JOAN :

It's, it's just like when I was there [sitting in the good-girl voice's chair] and I was feeling so vulnerable and weak, and then it seemed like these [two voices] coming together as two things ... two people coming together is like, and one and all of a sudden I felt like a lot stronger [reconceptualization IM]...

JOAN: I guess we can confront the issues and talk to $\mathrm{T}$. [husband] about it, it doesn't have to be so scary [reconceptualization IM].

In this example, the rebellious voice helped the good-girl feel stronger and therefore confront the issues that disturb her instead of giving in. The opposing voices appeared to be respectfully communicating with one another ('I wonder if it's a way to, to be supportive') and engaging in joint action ('I guess we can confront the issues and talk to T. [husband] about it').

This IM seemed to act as a meaning bridge, allowing both voices to serve as resources (Brinegar et al. 2006) - 'coming together as two things ... two people coming together' - thus becoming a source of flexibility in the self's meaning system, in so far as it appeared to enable a conditional dynamic movement between the opposites, rather than a fixation on one of them ( $\mathrm{J}$. Valsiner, personal communication, 16 May 2008). This is also akin to the concept of coalition of positions as proposed by Hermans and Hermans-Konopka (2010).

Thus, as reflected in these two cases, one pattern of overcoming mutual in-feeding promotes the escalating of previously silenced voices, and the inhibition of the dominant voice, whereas another pattern opens the space to negotiation between opposing voices, transforming the opposition through mutual regulation. Regardless of their differences in terms of dialogical outcome, both processes involve the development of a meta-position, present in the reconceptualization IM, which is 
capable of communicating openly and effectively with other positions, and having a function of management and coordination.

Reflecting about these two processes, we may hypothesize that the kind of resolution depends on the type of therapeutic strategies used and the problem the client is facing. Thus, specific strategies or exercises focused on fostering clients' reaction against the problem (e.g. cognitive restructuring in cognitive-behavioural therapy or externalization in narrative therapy) may support the dominance reversal, given the way therapists support a counter-position to the problem. Other strategies more centred on understanding and giving voice to different positions (e.g. two-chair dialogue) may facilitate cooperative dialogue between the positions involved.

Moreover, the case illustrations presented were very different from each other as far as the type of the problem clients were facing is concerned. Susan was coping with a very destructive situation as a victim of her partner's violence. Her situation in comparison with Joan's was much more severe and was clearly a situation of crisis (Roberts 2000). We wonder whether, in situations in which the suffering is very disturbing, as in Susan' case, the inhibition of the maladaptive dominant voice cannot be a necessary starting point to more complex changes. On the other hand, when the suffering is less intense, perhaps stimulating a cooperative dialogue between voices is an important resource to transform the dominant self-narrative.

\section{Implications for DST}

In this section we discuss two implications of our work for DST: the dialogical functions of reconceptualization, as a particular form of metaposition, and the way multiplicity in the self produces stability or change.

As the IMs change model suggests, reconceptualization is fundamental in transforming self-narratives. Reconceptualization IMs occurred in the clinical cases presented above, although, as we have also discussed, the paths of change were very different in these two cases. One important ingredient of reconceptualization IMs is the presence of a contrast between a past position and a current one, as well as access to the processes which allow the transformation from one to the other. As stated before, the articulation of the relationship between these two positions is only possible by a third one: a meta-position (see Hermans 2003). Recently, Hermans and Konopka (2010) have argued that metapositions have three main functions: unifying, executive and liberating. The unification refers to the way different $I$-positions are articulated or put in contact by the action of the meta-position. The executive function 
results from the decision-making processes, in which the meta-position has, at least temporarily, the power to organize the different positions involved. Finally, the liberating function has to do with the ability that the self has to stop habitual or automatic patterns associated with common positions and give priority to new ones, less automatic. In fact, these functions are very clear in reconceptualization: past and present have a temporal integration which gives meaning to the transition (unifying function), the present position is preferred and gets priority (executive function), and former habitual patterns, present in the dominant (problematic) self-narratives, are disrupted and stopped (liberating function).

One interesting phenomenon, from our perspective, is the repetition of reconceptualization in psychotherapy. As we stated before, reconceptualization emerges in successful psychotherapy in the middle of the treatment and increases until the end. In fact, quite often reconceptualization IMs represent the most common form of innovation in psychotherapy, occupying a significant amount of time. We believe that this repetition of different reconceptualization IMs is in fact therapeutic and no significant change would occur without it. Moreover, reconceptualization does not involve a meta-position between two current positions, but rather a meta-position that articulates a past position and an emerging new one. Thus, we propose that a fourth function of a metaposition is present here: a developmental one. That is, through the repetition of the meta-positioning involved in reconceptualization a disidentification with the past I-position occurs, concomitantly with a progressive identification with the emerging novelty, transforming the self in the process (Cunha et al. in press). This would explain the need of some redundancy of reconceptualization in psychotherapy (and perhaps also in every significant life transformation).

A second implication of our approach to the study of the dialogical self relates to the processes through which multiplicity of the self produces stability or change. This chapter shows that when uncertainty and ambivalence are not overcome throughout the therapeutic process, the dominant $I$-positions (present in the dominant narrative) and alternative ones (present in IMs) may establish a cyclical relation throughout the therapeutic process - a process of mutual in-feeding - blocking the development of the dialogical self. In such a case, 'the self-system is dynamic, but not developmental' (Valsiner 2002: 260).

This alternation between two opposite positions is more monological (at least as an outcome) than dialogical. This relates to a proposal from Hermans and Konopka (2010) about the nature of 'good dialogue'. 
Moreover, from their point of view, the presence of two or more positions (internal and/or external) does not guarantee that dialogue will occur. One of the features of good dialogue is the production of some form of innovation, in which each participant takes the other into consideration and is open to change their own perspective in response to the other. This is exactly what is absent when mutual in-feeding is not resolved. The two positions keep alternating without any resonance to the other's perspective. They are each of them closed inside itself, not responding to the other, but just reacting to the other. That is, in the response, the other position is not integrated, and the original position stays unchanged. Thus, a mere automatic reaction (and not a responsive response) keeps going on, as illustrated above.

We have shown two types of resolutions for these situations: one, in which one position is temporarily blocked, and the other develops, and the other, in which the two positions enter into dialogue. The last resolution is congruent with the notion of 'good dialogue'. Of course, our chapter illustrates that this might not always be possible, and that change may start when the problematic position is blocked. One interesting question that remains for future studies is whether, for solid therapeutic change to occur, 'good dialogue' must be present at some point of the process.

\section{ACKNOWLEDGEMENTS}

This chapter was supported by the Portuguese Foundation for Science and Technology (FCT), by Grant PTDC/PSI/72846/2006 (Narrative Processes in Psychotherapy) and by the Ph.D. Grant SFRH/BD/46189/ 2008. We are very grateful to Leslie S. Greenberg and Lynne Angus for allowing us to analyse the transcripts of Joan's case.

\section{NOTES}

1 The concept of IM is a methodological application of the concept of unique outcome proposed by White and Epston (1990) (see Gonçalves et al. 2009, for an explanation about this topic).

2 This original pseudonym of this case was 'Jan'. We changed the pseudonym here to 'Joan' since in several languages Jan is a male name.

3 Two-chair work has its roots in gestalt therapy as described by Perls et al. (1951) and has been adapted and further developed by Greenberg and colleagues (e.g. Greenberg et al. 1993). This therapeutic task involves identifying two discrepant (often conflicting) parts of the self, and putting each one on a separate chair. The client is then coached to speak for each of the parts in turn, thus creating a dialogue between the two parts. 


\section{REFERENCES}

Abbey, E. and Valsiner, J. (2005) Emergence of meaning through ambivalence [58 paragraphs]. Forum Qualitative Sozialforschung/Forum: Qualitative Social Research, 6(1), Art. 23. Retrieved from http://nbn-resolving.de/urn:nbn: de:0114-fqs0501231

Arkovitz, H. and Engle, D. (2007) Understanding and working with resistant ambivalence in psychotherapy, in S. G. Hofmann and J. Weinberg (eds), The Art and Science of Psychotherapy (New York: Routledge), 171-190

Bakhtin, M. (1984/2000) Problems of Dostoevsky's Poetics (Minneapolis, MN: University of Minnesota Press)

Brinegar, M. G., Salvi, L. M., Stiles, W. B. and Greenberg, L. S. (2006) Building a meaning bridge: therapeutic progress from problem formulation to understanding, fournal of Counselling Psychology, 53, 165-180

Cooper, M. (2004) Encountering self-otherness: 'I-I and 'I-Me' modes of self relating, in H. J. M. Hermans and G. Dimaggio (eds), The Dialogical Self in Psychotherapy (New York: Brunner-Routledge), 60-73

Cunha, C., Gonçalves, M., Ribeiro, A. P., Mendes, I. and Valsiner, J. (in press) Rehearsing renewal of identity: re-conceptualization on the move, in M. C. Bertau, M. Gonçalves and P. Raggatt (eds), The Dialogical Self in Developmental Perspective (Charlotte, NC: Information Age Publishing)

Dimaggio, G. and Lysaker, P. (eds) (2010) Metacognition and Severe Adult Mental Disorders: From Basic Research to Treatment (London: Routledge)

Dimaggio, G., Salvatore, G., Azzara, C. and Catania, D. (2003) Rewriting self-narratives: the therapeutic process, fournal of Constructivist Psychology, 16, $155-181$

Ecker, B. and Hulley, L. (2000) The order in clinical disorders: symptom coherence in depth-oriented brief therapy, in R. A. Neimeyer and J. D. Raskin (eds), Construction of Disorder: Meaning-Making Frameworks for Psychotherapy (Washington, DC: American Psychological Association), 63-89

Gonçalves, M. and Guilfoyle, M. (2006) Dialogism and psychotherapy: therapists' and clients' beliefs supporting monologism, fournal of Constructivist Psychology, 19, 251-271.

Gonçalves, M., Matos, M. and Santos, A. (2009) Narrative therapy and the nature of 'innovative moments' in the construction of change, fournal of Constructivist Psychology, 22, 1-23

Gonçalves, M., Ribeiro, A., Conde, T., Matos, M., Martins, C., Santos, A., et al. (in press) The role of mutual in-feeding in maintaining problematic self-narratives: exploring one path to therapeutic failure, Psychotherapy Research. doi: 10.1080/10503307.2010.507789

Gonçalves, M., Ribeiro, A., Matos, M., Santos, A. and Mendes, I. (in press) The innovative moments coding system: a coding procedure for tracking changes in psychotherapy, in S. Salvatore, J. Valsiner, S. Strout and J. Clegg (eds), YIS: Yearbook of Idiographic Science, vol. 2 (Rome: Firera Publishing Group)

Gonçalves, M., Santos, A., Salgado, J., Matos, M., Mendes, I., Ribeiro, A., et al. (2010) Innovations in psychotherapy: tracking the narrative construction of 
change, in J. D. Raskin, S. K. Bridges and R. Neimeyer (eds), Studies in Meaning 4: Constructivist Perspectives on Theory, Practice, and Social fustice (New York: Pace University Press), 29-64

Greenberg, L. S., Rice, L. N. and Elliott, R. (1993) Facilitating Emotional Change: The Moment-by-Moment Process (New York: Guilford)

Greenberg, L. S. and Watson, J. (1998) Experiential therapy of depression: differential effects of client-centred relationship conditions and process interventions, Psychotherapy Research, 8, 210-224

Hermans, H. J. M. (1996a) Opposites in a dialogical self: constructs as characters, fournal of Constructivist Psychology, 9, 1-26

(1996b) Voicing the self: from information processing to dialogical interchange, Psychological Bulletin, 119, 31-50

(2003) The construction and reconstruction of a dialogical self, fournal of Constructivist Psychology, 16, 89-130

(2004) The dialogical self: between exchange and power, in H. J. M. Hermans and G. Dimaggio (eds), The Dialogical Self in Psychotherapy (New York: Brunner-Routledge), 13-28

Hermans, H. J. M. and Dimaggio, G. (2007) Self, identity, and globalization in times of uncertainty: a dialogical analysis, Review of General Psychology, 11, 31-61

Hermans, H. J. M. and Hermans-Jansen, E. (1995) Self-Narratives: The Construction of Meaning in Psychotherapy (New York: Guilford)

Hermans, H. J. M. and Hermans-Konopka, A. (2010) Dialogical Self Theory. Positioning and Counter-Positioning in a Globalizing Society (Cambridge University Press)

Hermans, H. J. M. and Kempen, H. J. G. (1993) The Dialogical Self: Meaning as Movement (San Diego, CA: Academic Press)

Honos-Webb, L., Surko, M., Stiles, W. B. and Greenberg, L. S. (1999) Assimilation of voices in psychotherapy: the case of Jan, fournal of Counselling Psychology, 46, 448-460

Kelly, G. A. (1995) The Psychology of Personal Constructs (New York: Norton)

Linell, P. and Marková, I. (1993) Acts in discourse: from monological speech acts to dialogical inter-acts, fournal for the Theory of Social Behaviour, 23, 173-195

Mahoney, M. (1991) Human Change Processes: The Scientific Foundations of Psychotherapy (New York: Basic Books)

Matos, M., Santos, A., Gonçalves, M. and Martins, C. (2009) Innovative moments and change in narrative therapy, Psychotherapy Research, 19, 68-80

McAdams, D. P. (1993) The Stories We Live By: Personal Myths and the Making of the Self (New York: William Morrow)

Michel, A. and Wortham, S. (2002) Clearing away the self, Theory E Psychology, 12, 625-650

Neimeyer, R., Herrero, O. and Botella, L. (2006) Chaos to coherence: psychotherapeutic integration of traumatic loss, fournal of Constructivist Psychology, 19, 127-145

Perls, F., Hefferline, R. and Goodman, P. (1951) Gestalt Therapy (New York: Julian Press) 
Ribeiro, A. and Gonçalves, M. (2010) Innovation and stability within the dialogical self: the centrality of ambivalence, Culture and Psychology, 16, $116-126$

Roberts, A. (2000) Crisis Intervention Handbook (Oxford University Press)

Rosa, C. and Gonçalves, M. (2008) Dialogical self and close relationships: looking for ambivalences, Studia Psychologica, 8, 89-108

Salgado, J. and Gonçalves, M. (2007) The dialogical self: social, personal, and (un)conscious, in J. Valsiner and A. Rosa (eds), The Cambridge Handbook of Sociocultural Psychology (Cambridge University Press), 608-621

Santos, A. and Gonçalves, M. (2009) Innovative moments and change processes in psychotherapy: an exercise in new methodology, in J. Valsiner, P. C. M. Molenaar, M. C. D. P. Lyra and N. Chaudhary (eds), Dynamic Process Methodology in the Social and Developmental Sciences (New York: Springer), 493-526

Sarbin, T. R. (1986) The narrative and the root metaphor for psychology, in T. R. Sarbin (ed.), Narrative Psychology: The Storied Nature of Human Conduct (New York: Praeger), 3-21

Valsiner, J. (2000) Culture and Human Development: An Introduction (London: Sage)

(2002) Forms of dialogical relations and semiotic autoregulation within the self, Theory \& Psychology, 12, 251-265

(2004) Temporal integration of structures within dialogical self, keynote lecture at the 3rd International Conference on the Dialogical Self, Warsaw

(2008) Constraining one's self within the fluid social worlds, paper presented at the 20th Biennial ISSBD meeting, Würzburg

Valsiner, J. and Sato, T. (2006) Historically structured sampling (HSS): how can psychology's methodology become tuned into the reality of the historical nature of cultural psychology?, in J. Straub, C. Kölbl, D. Weidemann and B. Zielke (eds), Pursuit of Meaning: Theoretical and Methodological Advances in Cultural and Cross-Cultural Psychology (Bielefeld: Verlag für Kommunikation, Kultur und Soziale Praxis), 215-251

White, M. and Epston, D. (1990) Narrative Means to Therapeutic Ends (New York: Norton)

Zittoun, T. (2007) Dynamics of interiority: ruptures and transitions in self-development, in L. M. Simão and J. Valsiner (eds), Otherness in Question: Labyrinths of the Self (Charlotte, NC: Information Age Publishing), 187-214

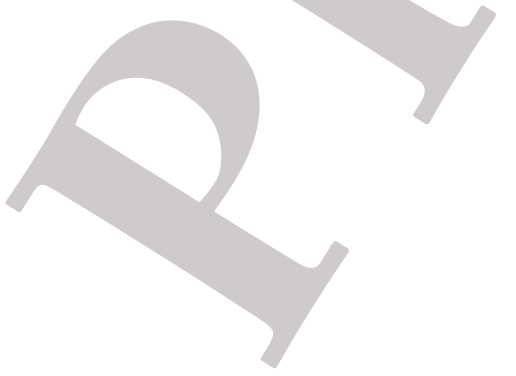

